\title{
Conceptualizing Structures for Urban Tourism in Kenya A Strategy for Enhancing Entrepreneurship
}

\author{
Francis Wambalaba E Akosa Wambalaba
}

\begin{abstract}
In the late 1990s, the City of Portland, Oregon in the United States decided to explore the potential for attracting tourists in its urbanized areas. It therefore carried out a study in select urban areas in the country to identify transport oriented features that would enhance access to urban tourist attraction sites. A transport service design was developed and when it was completed, one of the unexpected outcomes was a thematic nature for selected service routes. A uniquely painted bus (hence referred to as "the cultural bus") along with select customer friendly drivers were assigned on a route to cater for tourists. The number of tourists using the thematic bus route shot up and so was patronage of businesses along the route.
\end{abstract}

But unlike the Portland example, the tourist industry in Kenya, along with its stakeholders have traditionally focused tourist infrastructure on a few large attractors (high impact sites), and very little has been done to maximize on the marginal sites (low impact sites), especially in urbanized areas.

The objective of this paper is to provide a context for conceptualizing natural and infrastructural structures for urban tourism and entrepreneurial opportunities in Kenya by; 1) reviewing the premises and design contexts of urban tourism, 2) presenting transport oriented guiding principles for urban tourism, and 3) documenting pertinent transport design and practices case studies from the United States. The paper is an applied case study based on some of the projects in which the authors were previously either directly engaged in or responsible for documenting the practices. It also conceptualizes the nature of urban spatial structure and analysis pertinent to urban tourism.

\section{Background}

A United Nations report has pointed out that tourism in Kenya dates back to preindependence days and history has it recorded that as early as the 1930's, overseas visitors and explorers had started coming to Kenya mainly for big-game hunting expeditions while others came in search of solitude. These expeditions were locally referred to by the Swahili word "Safari" thus bequeathing to the travel world literature with a new vocabulary. Among the early visitors were Statesmen, Royalties and celebrities such as Theodore Roosevelt, Her Majesty Queen Elizabeth II, and Ernest Hemingway respectively. ${ }^{1}$

While recent trends have shown efforts towards diversity, urban tourism has tended to be a bi-product of game and beach tourism. As the UN report has indicated, at independence the accent was on encouraging specialized groups from the upper

\footnotetext{
${ }^{1}$ http://www.un.org/esa/agenda21/natlinfo/niau/kenyanp.htm
} 
segment of the market to visit the country for big game hunting expeditions and beach tourism. The focus later shifted to target the middle income segment of the market to visit the coastal resorts which today accounts for over $60 \%$ of visitors to Kenya. These tourists took advantage of the inclusive package tour arrangements to visit the country in large numbers giving rise to high volume tourism in Kenya.

The problem however is that, there is an over-concentration of tourist activities in some areas of the country, notably the Coastal beaches of the North Coast and Diani areas in the South Coast as well as in some National Parks and Game Reserves (high impact sites). Secondly, given that the tourist industry is strongly influenced by transportation (access), areas without systematic and organized transport infrastructure tend to lose out on tourism (low impact sites). And finally, urbanized areas that may even be well served by transport infrastructure may also lose out on tourism due to lack of context or value added.

Therefore, without a thematically designed transport to link urban low impact sites, tourists may never be able to spend to their full potential, not to mention some of the tourists returning from high impact sites that may have left-over money that could be spend in low impact sites if there were a thematic service provided. Hence, it can be argued that Kenya has done a fair job attracting tourists to enjoy its natural wildlife (high impact sites) as evidenced by public/private infrastructure that exists in support of that segment of the industry. However, it has not maximized the existing potential, especially in urbanized areas (low impact sites) as similarly evidenced by lack of comparable public/private infrastructure. It is therefore argued that a more systematic approach is needed to maximize existing potential. This would require the development of urban tourism oriented public/private infrastructure.

The strategy for urban tourism should be to provide opportunities for optimizing tourist revenue generation by; 1) capitalizing on thematic transport links, 2) developing multiple tourist market segmentations, and 3) capturing the full potential of tourist expenditures. The problem with the current conceptualization of Kenya's tourist industry is its emphasis on natural physical attributes. While in the early stages of tourism, the natural physical attributes tend to dominate the structure of tourism; this alone is not exhaustive, especially towards the mature stage of the industry. In these later stages of tourism, combinations of natural and infrastructural physical and mental attributes are necessary. Hence the need to create both infrastructure and mental attributes in urbanized areas where they tend to be lacking.

By offering such differentiated products that appeal to multiple markets, each market segment is able to maximize its utility by choosing the most for a given budget, while each service provider is able to maximize its revenues by capturing a marginal consumer who is able to spend up to their last shilling on tourism. It would therefore be anticipated that, a consumer who has maximized their utility may likely be a return customer and/or a promoter of the Kenyan tourism experience. Likewise, it is anticipated that a service provider who has maximized their revenue may likely be a stable purchaser of local input resources. Ultimately, the generation of these economic activities may spur other local socio-economic developments, not to 
mention tax revenues for public infrastructure that may further enhance the potential of the tourist industry's growth in Kenya and Africa, as a whole.

Therefore there is need for exploring potential design concepts, principles and practices towards urban tourism by:

- Reviewing the premises and design contexts of urban tourism.

- Presenting transport oriented guiding principles for urban tourism.

- Documenting pertinent transport design and practices case studies.

\section{Urban Tourism Premises and Design Concepts}

The concept of Urban Tourism has been growing in importance around the world as may be evidenced in specialized literature around the subject. According to some, the demand for travel to cities has greatly increased over the last few decades. While many travel for business or convention purposes, others travel for leisure to learn about other cultures, to develop their specific interests, and to seek entertainment. They distinguish between primary, secondary, and additional elements of a city's tourism resources. Primary elements provide the main reasons why tourists visit cities. Secondary elements include accommodation and shopping. They also add that additional elements like transportation or tourist information are also very important for the success of urban tourism, even though they are not the main attractor of visitors.

Others who have written about Urban Tourism offer a holistic analysis of tourism as an urban phenomenon and the challenge of developing, harnessing, and managing urban tourism. They identify critical linkages with all aspects of tourism and other subjects that make theoretical developments in urban social theory very accessible. They also look at the practical level in relation to the development of urban studies and planning knowledge to help the reader understand what urban tourism is.

\section{Developments in Urban Tourism Premises}

According to the Europe Commission (2000), renewed interest in urban tourism since the beginning of the 1980s has brought about a sharp upturn in this kind of tourism. Various interlinked factors have played a part in this: 1) the need to breathe life back into and rehabilitate the historic centers of towns and cities, 2) wider-ranging and more diversified cultural pursuits, 3) consumers' interest in the heritage and urban development, and 4) their search for things to do and for spending opportunities. But the broader range of activities and leisure pursuits that visitors are seeking requires extending what is typically offered. Such diversification is also due to a growing awareness of tourism among political decision-makers who are increasingly keen to promote it as a key factor in economic development bringing wealth and employment. Tourism is seen as a cornerstone of a policy for urban 
development that combines a competitive supply able to meet visitors' expectations with a positive contribution to the development of towns and cities and the well-being of their residents.

And according to the 1999 Trade Environmental Database (TED), the most recent trends and forecasting studies by the World Trade Organization indicate that cities will continue to be in high demand by tourists of all sorts, and the problems associated with the handling of these tourists will have to be more systematically tackled by all parties concerned. ${ }^{2}$ Therefore, cities face a number of challenges, namely:

- They have to be able to respond to the expectations and needs of the growing number of tourists who are attracted to their rich and varied array of cultural, business, entertainment, shopping, sports and other attractions.

- They need to continuously renovate and improve such facilities in order to maintain their share in the competitive tourism market and the benefits resulting from it.

- They have to ensure that tourism is developed and managed in such a way that it benefits the resident population, does not contribute to the deterioration of the urban environment but rather to its enhancement, and does not become a financial burden to the local authority.

\section{Survey of Urban Tourism Design Concepts}

A lot of literature across continents signifies this growing importance of the urban tourist market segment. Below is a sample of comments from around the world along with suggestive features for local authorities to consider.

1. North America: In her book, Doing the Town Catherine Cocks presents the historical changing image of "American Cities" indicating that tourists and travelers in the early nineteenth century saw American cities as ugly spaces, lacking the art and history that attracted thousands to the great cities of Europe ${ }^{3}$. But by the turn of the century, city touring became popular in the United States, and the era saw the rise of elegant hotels, packaged tours, and train travel to cities for vacations that would entertain and edify. Focusing mainly on New York, San Francisco, Washington, D.C., and Chicago, she described what it was like to ride on Pullman cars, stay in the grand hotels, and take in the sights of the cities. Thus, rather than merely places to live and work, cities took shape as places to visit. The book covers cultural history and details of Victorian-era travel, explores the beginnings of urban tourism, and sets the phenomenon within a larger cultural transformation that encompassed fundamental changes in urban life and national identity.

\footnotetext{
${ }^{2}$ Conference on "Tourism and the City: The Challenge of Sustainability" from 10 to 12 November 1999 in Madrid, Spain.

${ }^{3}$ Catherine Cocks, “Doing the Town: The Rise of Urban Tourism in the United States, 1850-1915” http:// www.ucpress.edu/books/pages/9260.html
} 
40 Francis Wambalaba \& Akosa Wambalaba

2. Europe/United Kingdom: According to the British Tourist Authority (2000), urban tourism in UK benefits from city break. A city break is a short holiday, usually lasting between one and four days, sometimes longer. The city break market is concentrated on a relatively small number of cities and is fiercely competitive. Paris and Amsterdam are the most popular destinations, with additional European competition coming from Bruges, Brussels, Rome, Barcelona, Venice, Prague, London, Dublin, as well as Edinburgh and Glasgow. Scotland has a strong city break market centered on Edinburgh and Glasgow.

3. Asia/Korea:. Suh \& Gartner (2004) have argued that the study of urban tourism has not received as much attention as the magnitude of this phenomenon would seem to indicate. Their study explored visitor perceptions of Seoul, Korea, held by three different nationalities and also by purpose of visit (i.e., pleasure vs. business). Perceptual mapping was utilized to differentiate between preferences shared by the six groups.

4. Latin America/Brazil: A case study in Latin America has focused on the link between urban tourism and the local culture ${ }^{4}$. The purpose of the study was to address the impact of the tourist industry, through the transformation of urban areas for tourist consumption and entertainment, on the primarily Afro-Brazilian working class and poor. The case study looked at the impacts of the tourist trade on both culture and the environment in Salvador, Brazil. It considered "culture" as an important reason for why tourists go to Bahia. The tourist industry in the state markets Bahia's strong Afro-Brazilian heritage to both Brazilian and foreign visitors.

5. Africa/Tanzania: Lawrence (2005) writing about urban tourism in Tanzania argues that it is a fact that a well planned town with attractive buildings and arranged streets do attract a number of tourists, but preservation of old structures is crucial so as to retain the historical perspective of the past generation as well as attracting tourists. He advances that poor planning in most African countries is catalyzed by poverty, but the presence of slums and plastic roofed shacks in many urban centres in developing countries is nothing but the inability of authorities to meet the demands of the population in acquiring plots for erecting dwellings and business premises.

\section{Transport Oriented Guiding Principles for Urban Tourism}

In view of the above literature, it seems that while the private sector may be able to provide opportunities for urban tourist sites, it remains the responsibility of national and local governments to provide the necessary infrastructure and context that promotes urban tourism. Because tourism must, according to any definition, be concerned with the movement of people, transport is a fundamental part of it. However, as tourism develops into an important industry, and competition increases in the global tourism market place, a wide range of quality transport options are

\footnotetext{
${ }^{4}$ Trade Environment Database (TED), Urban Tourism's Impact on Colonial Areas of Latin American Cities:
} The Case of Salvador, Brazil, http://www.american.edu/TED/urbtour.htm 
necessary to maximize the industry's potential. Kenya's tourism industry will need to identify applicable features from around the world and not only emulate them, but also improvise. Some of the potential transport oriented guiding principles from the United Kingdom are presented below.

1. The British Tourist Authority: According to the British Tourist Authority (2002), it has been argued that an over-emphasis on 'smoothing the way for road traffic' by successive post war UK governments has 'left Britain with an inferior public transport system, which proves a disadvantage in the effort to attract tourism, especially in direct competition with neighboring European nations'. It further points out that the Scottish Tourism Forum in their Tourism Strategy Review Response argued for the 'urgent need to develop and commit to a long term plan of investment to ensure that Scotland's competitiveness is not eroded by inadequate transport links to and within Scotland'. It is further argued that when tourists have a limited time scale, they want to feel that they can get to their intended destination as quickly as possible. Typically, overseas visitors are heavily dependent on the transport system, which has a critical role in spreading the benefits of tourism to all parts of the city by making it easy for tourists to travel more widely.

However, transportation cannot be done in isolation but as we have seen in the US examples, as a system with a theme. Tourists need good information services, integrated ticketing, reliable services and good interchange between networks. Unlike for locals, these services are far more acute because tourists are usually unfamiliar with the system and may speak a foreign language, are pressed for time and may be handling heavy luggage.

2. British Tourism Development Committee: Kenya could also take note from UK's policy report. The 2001 British Tourism Development Committee's policy report on Enabling Success argues that 'an intuitive, reliable, safe, affordable, and wellmarketed transport system' is necessary and should take account of the needs of overseas visitors. It recommends the following action points:

- Ensure that transport planning strategies meet the needs of overseas visitors, thereby meeting the needs of everyone else and providing an excellent litmus test for integration policies.

- Improve the services, facilities and quality of welcome provided to overseas visitors on arrival at ports-of-entry as "First Impressions".

- Make airports into true transport hubs by integrating surface transport links into the terminal structure rather than relying on transfer services.

- Upgrade transport infrastructure to accommodate the needs of visitors: adequate space for luggage; and assistance for the elderly, those with disabilities, those with small children and all those with heavy luggage. 
- Encourage greater integration of timetable and availability of tickets/travel cards that are interchangeable across different transport modes.

- Expand public transport infrastructure, services and information at sites to alleviate car congestion and spread visitors more widely.

- Encourage co-ordination of transport timetables with tourism activity/events and provision of more packages combining travel and admissions to events or attractions.

3. Scottish Tourism Forum: Like the British Tourism Development Committee, the Scottish Tourism Forum believes that transport integration is vital to any tourism product:

- Transport integration remains a priority and operators across different transport modes must work harder to improve service connections.

- Co-ordination between operators must be encouraged and through-ticketing to support passenger transfers between different modes is necessary.

- Sometimes there are occasions when ferries, flights, rail and bus still do not connect well for the customer.

- The fact that bicycles cannot be carried on many train services is a disservice and inconvenience to many customers.

- $\quad$ The combined objective must be to ensure safe, convenient and affordable transit by train and therefore encourage transfer from other modes, predominantly the car, to and around the cities and Central Belt, and use of the train to access rural and remote areas, to help encourage tourism growth in these areas.

\section{Urban Tourism Transport Design and Practices: The US Case Studies}

There are varied approaches to urban tourism transport design and practices. In terms of themed transportation oriented approaches, a sample of four cities are used here to demonstrate how the same strategies could be employed in Kenya to enhance urban tourism. These include Boston in Massachusetts, Philadelphia in Pennsylvania, Miami in Florida, and Portland in Oregon.

1. Boston, Massachusetts: One of the key themed services is the Boston Duck Tours. This service was designed to use the World War II landing craft for tours, for both on land and water. The craft takes tourists to the edge of the Charles River and drives right in. The tour bus then becomes a tour boat, and the tourists get a duck's-eye view of Boston and Cambridge from water.

The thematic water experience of the Duck Tours is designed to provide a wonderful way to get a fresh look at the city, and have a blast doing it. It is geared to combine highenergy, fun energy with a unique perspective on all the history that makes Boston a 
great town. In the thematic land experience, it is anticipated that during the 80minute tour, one can see the gold-domed State House, the Newbury Street, and much more.

In addition to the Boston Duck Tours, another themed service is the "Trolley Tours". The Trolley Tours service is Boston's most comprehensive tour, fully narrated by expert guides and covering all of Boston's highlights.

This service is designed such that one can tour at their own pace with freedom to disembark and re-board at any of the 19 stops and may travel around the loop as many times as they like. Thus, while Boston is a compact city, it's also a city of distinct neighborhoods, and these trolley tour services are designed to capture that diversity. For example, the Red Beantown Trolley Tour ties Boston together to get a sense of the city as a whole with all its charm and history. During the 110-minute Beantown Trolley tour, the message is "sit back and relax".

2. Philadelphia, Pennsylvania: Philadelphia's Phlash is a purple trolley that makes 20 City Center stops from Penn's Landing to the Art Museum. It's a convenient way to get around city attractions, historic landmarks and most downtown hotels. The Phlash stops every 12 minutes at route destinations. The ride between Penn's Landing and the Philadelphia Museum of Art includes dropping passengers off at or near most popular tourist destinations along; Market Street and the Benjamin Franklin Parkway.

The Phlash is managed by the Center City District but is operated by the Philadelphia Trolley Works. One million tourists and residents had taken the Phlash since the service was introduced in 1997.

3. Miami, Florida: The Miami Electrowave service was initiated on January 30, 1998. The fleet of eleven shuttles was moving works of art with murals and other designs across the vehicle's panels. The objectives of the service were to; 1 ) allow residents and visitors to more conveniently enjoy the South Beach area, and 2) reduces traffic congestion, parking problems and air pollution. The Vehicle is an electric shuttle designed to travel up to 8 hours on a single battery charge. All of the vehicles are air conditioned, have large unobstructed windows, cushioned wrap-around seating, music, and courteous drivers specially trained in customer service for the area.

The planning process involved extensive analysis of the local business activity, traffic patterns, parking availability, and resident and visitor activities and preferences. A Private-Public Partnership strategy was used, especially in the funding including the Miami Business Transportation Management Association, the City of Miami Beach, Florida Department of Transportation, Florida Power and Light, Florida Alliance for Clean Technologies, Clean Cities, the Florida Department of Environmental Protection, and the International Council for Local Environmental Initiatives (ICLEI). 
4. Portland, Oregon: Portland's Cultural Bus, which is also referred to as "ART, The Cultural Bus" has been defined as "a kinetic, three-dimensional, interactive piece of art that transports visitors to many of Portland's attractions". It all started in the 1990s, when the City of Portland decided to explore potential for attracting tourists in its urbanized areas. A study in select urban areas to identify transport oriented features that enhanced access to urban tourist attraction sites was done.

A service design was developed with a thematic nature for selected service routes, a uniquely painted bus referred to as "the cultural bus", and customer friendly drivers assigned on a route.

Other additional service features include the purchase of the Portland Attractions Pass at the Visitor Information Center at Pioneer Courthouse Square that is valid on other transport services. The service was designed so as to connect to other bus, light rail and streetcar services without requiring extra fare that would take riders to other further off sites. One such a site is Portland's "End of Oregon Trail Interpretive Center which includes a 30-minute original film "the Bound for Oregon", exhibits, and an interactive, "please-touch" activities.

Similarly, in the central business district, service on all TriMet buses, MAX light rail, and the Portland Streetcar are free. Thus, throughout this 330-block downtown "Fareless Square," passengers ride free of charge

\section{Conclusion}

In the context of urban tourism, transport access by itself without a thematic context may not be an effective tool for enhancing urban tourism. As it was earlier pointed out, urbanized areas that are well served by transport infrastructure may lose due to lack of a systematic and organized transport infrastructure that provides context or value added For example, a thematic approach, such as the development of a "Nairobi Cultural Shuttle" may add value to several of Nairobi's potential urban tourist attractor sites. This would not only translate the physical attributes into psychological attractors, but it would also emphasize institutionalization of the process.

It is also argued here that in fact, some of the tourists returning from high impact sites with left-over money could spend it in urbanized low impact sites if there were a thematic service provided. Hence, without a thematically designed transport to link urban low impact sites, tourists may never be able to spend to their full potential.

The problem we face is that almost all hotel and tour operators have a myriad of promotional transport packages for sites such as Maasai Mara, Mt. Kenya, Mombasa beaches, Lakes Nakuru and Naivasha etc. However, none has tried to look into exclusive transport opportunities in urbanized areas to places such as, Nairobi's Museum, Safari Walk, Arboretum, Bomas of Kenya, the Village Market, Limuru Coffee \& Tea farms etc. While such low impact sites are frequented by locals, their enhanced access as tourist sites would not only provide a new insight for tourists about the typical sites frequented by locals, but would also be an opportunity for them to interact with locals (unlike the high impact sites where such interaction is only limited to service providers and a few high income locals). These low impact 
sites may also cater for budget conscious tourists who may not be able to afford the high impact sites.

It is therefore recommended that to effectively maximize tourism in Kenya, we must embark on the development and promotion of urban tourism. It is further argued that a thematic approach similar to the Portland model and other examples covered in this research would be a competitive option since it would translate the physical attributes into psychological attractors. It is also the view of this study that urban tourism is not a substitute to game or beach tourism, but it should be treated as critical link to make the tourist experience whole, while also boosting spending further.

\section{References}

British Tourist Authority, (2002), Inbound Tourism to the UK: A Competitive Assessment (London: British Tourist Authority.

Cadwallader, Martin, (1985), Analytical Urban Geography, Prentice Hall Inc.

Catherine Cocks, "Doing the Town: The Rise of Urban Tourism in the United States, 1850-1915" http://www.ucpress.edu/books/pages/9260.html

European Commission, (2000), Towards Quality Urban Tourism: Integrated Quality Management (IQM) of Urban Tourist Destinations, Enterprise Directorate-General Tourism Unit, Luxembourg: Office for Official Publications of the European Communities.

Government of Kenya, (1969), Kenya National Tourism Master Plan beyond 2000

Government of Kenya, Sessional Paper No.8 on the Development of Tourism in Kenya

Lawrence, F., (2005), Dar City Needs Urban Tourism, Sunday, July 24, http:// florence3.blogspot.com/2005/07/dar-city-needs-urban-tourism.html

Omondi, P., Odhiambo, M., Wangila, B., and Ogbu, O, (2000), "Investigating the Impact of Tourism in Kenya", International Development Research Centre, http:/ Lwww.idrc.ca/en/ev-5332-201-1-DO_TOPIC.html

Page, Stephen J. \& Hall, Michael C., (2002), Managing Urban Tourism: Themes in Tourism, Prentice Hall / Pearson Education.

Ruetsche, Judith, (2006), What Attracts Visitors to Cities? Urban Tourism, Issue 117

http://www.uwex.edu/CES/CCED/lets/LTB0506.pdf.

Suh, Yong K., and Gartner, William C. (2004), “Perceptions in International Urban Tourism: An Analysis of Travelers to Seoul, Korea" Journal of Travel Research, Vol. 43, No. 1, 39-45.

Trade Environment Database (TED), Urban Tourism's Impact on Colonial Areas of Latin American Cities: The Case of Salvador, Brazil, http://www.american.edu/ TED/urbtour.htm

UN Report, "Sustainable Tourism in Kenya", http://www.un.org/esa/agenda21/ natlinfo/niau/kenyanp.htm. 